\title{
The role of attachment in medically unexplained symptoms and long-term illness
}

\author{
Gwen Adshead \& Elspeth Guthrie
}

\begin{abstract}
SUMMARY
In this article, we explore the role of attachment in the development of medically unexplained symptoms (MUS) and response to physical illness. We review the evidence that attachment insecurity is common in people with different forms of MUS and certain long-term physical conditions. We discuss a possible developmental model for understanding how MUS develop. We conclude with discussion of potential therapies and implications for services.
\end{abstract}

\section{LEARNING OBJECTIVES}

- Increased knowledge of the theoretical basis of attachment theory and the major different patterns of attachment

- Increased awareness of the complexity of the link between insecure attachment and development and maintenance of MUS and long-term illness

- Increased ability to recognise and take account of specific patterns of interpersonal relating in patients with MUS, to help formulate treatment and management plans

\section{DECLARATION OF INTEREST}

None

Medically unexplained symptoms (MUS) are common in primary and secondary care. There is a wide spectrum of presentation, from relatively mild and transient symptoms to more severe and persistent states. MUS are associated with considerable healthcare and societal costs, including increased use of healthcare services, over-investigation of symptoms, delivery of ineffective treatments, considerable sickness absence and significant disability benefit payments. Addressing MUS is a priority for NHS England, and current plans involve delivering treatment via the Improving Access to Psychological Therapies (IAPT) programme (IAPT 2015).

Hartman et al (2013), in guidelines prepared for Dutch general practitioners, review the wide range of theoretical models suggested as underpinning MUS, and briefly mention the possible role of early attachments. There is now an extensive body of evidence that insecurity of attachment is related to both the onset of illness and disease, and the ways that people interact with healthcare services (Maunder 2008).

In this article, we focus on attachment theory as a heuristic framework. This is not to dismiss other theories, but because we think it is a theory that has particular practical value for clinicians in terms of treatment and clinical role. MUS are perplexing disorders that involve not just the individual concerned, but also their relationships with healthcare professionals, and the language of distress and medical processes (Eriksen 2013).

We include reference to research addressing the relationship between attachment security and the ways that people with long-term organic physical disease seek care from healthcare professionals. There are important parallels between how people respond to enduring physical symptoms that have an organic cause and how they respond to symptoms that are medically unexplained. In clinical settings, patients often present with symptoms of both types rather than one or the other. Attachment theory helps in understanding not only how conditions may develop, but also how they may become persistent and enduring. Understanding the pathogenesis of MUS is an important step in developing management and care pathways for these complex conditions.

\section{Background}

Medically unexplained symptoms is a term used to refer to bodily symptoms such as headache, fatigue and abdominal pain that cannot be explained by a recognised physical disease, and it includes a range of different symptoms and presentations. In primary care, the prevalence of MUS is thought to be between 10 and 30\%; in secondary care the prevalence is even higher, with presentations of MUS accounting for between 35 and $55 \%$ of all new medical out-patient referrals (Creed 2011a). Particularly high rates of MUS have been reported in neurology clinics (Stone 2009), in patients both with and without neurological disease (Sharpe 2010). It is important to be aware that MUS
Gwen Adshead is a locum consultant forensic psychiatrist with Southern Health NHS Foundation Trust. She has regularly assessed parents with personality disorders for the family courts and is involved in evaluating a therapy group for mothers with personality disorder Elspeth Guthrie is Professor of Psychological Medicine and Medical Psychotherapy, Manchester Mental Health and Social Care Trust. Correspondence Dr Gwen Adshead, Locum Consultant Forensic Psychiatrist, Ravenswood House, The Knowle, Fareham P017 5NA, UK. Email: gwen.adshead@ southernhealth.nhs.uk 
commonly occur in people who have recognised physical illness but their 'symptoms' cannot be explained by the underlying physical disorder (e.g. non-epileptiform seizures in patients with known epilepsy) or the disability associated with the symptoms is far greater than expected.

Medically unexplained symptoms vary in severity, from mild to severe. They tend to cluster into subgroups, and many so-called functional somatic syndromes such as chronic fatigue syndrome, irritable bowel syndrome and fibromyalgia are considered to be part of the MUS spectrum (Aggarwal 2006). There is much overlap between these conditions, but there are also clear differences in pathogenic pathways (Hamilton 2009). For example, gastroenteritis is a risk factor for the development of irritable bowel syndrome but not for chronic fatigue syndrome. There is conflicting evidence as to whether these conditions reflect a general underlying tendency to 'somatise' (i.e. focus on bodily symptoms) or whether they are discrete, separate conditions.

Both physical and psychological factors may play a role in the pathogenesis of these disorders. MUS are more common in women and they are often comorbid with depression and anxiety. There is increasing evidence that certain conditions may be triggered by an inflammatory response, such as a gut infection, which then develops into a functional somatic syndrome. Those most at risk of this happening are people who report psychological distress or vulnerability at the time of the index infection (Gwee 1996).

Medically unexplained symptoms are distinguished from other abnormal illness behaviours such as malingering for profit or active deception of professionals for some other purpose. Individuals with MUS are genuinely experiencing physical distress - just not the kind that is usually caused by recognised organic disease. As both patients and therapists attest, the pain and bodily distress are real to the individual, and it can be hard to distinguish symptoms that are medically explained from those that are not.

\section{Relevance of attachment systems as caregiving and care-eliciting systems}

The attachment system is a neurophysiological system found in social mammals, including nonhuman primates, and associated with a range of social behaviours, including caregiving to off-spring and care-eliciting from others. In human infants, attachment behaviours are activated at times of stress and distress and are usually manifested as care-seeking behaviours such as vocal cries and seeking proximity to an identified attachment figure.
The attachment figure reciprocates with caregiving behaviours: usually reduced distance and physical soothing that reduces distress and arousal. Over time, the infant learns to self-soothe when distressed, possibly by developing psychological cognitive representations of soothing and comfort that can be activated either consciously or unconsciously. In adulthood, the individual will use those childhood representations as a basis for beliefs about whether they are worthy of care (model of self) and whether others can be trusted to provide care (model of other) (Fig. 1).

Studies of relationship behaviours between infants and carers (e.g. Ainsworth 1970) have established that it is possible to reliably identify both secure and insecure attachment systems. Insecurity of attachment in childhood has been shown in both animal and human studies to persist across the lifespan and affects relationships with others in adulthood. Patterns of attachment security and insecurity are similar in all human populations, regardless of gender, class or culture.

Insecurity of attachment is not in itself a pathology, but it represents a vulnerability in terms of effective stress and distress management. It is common in the general population; large meta-analytical studies suggest that $40 \%$ of the population have an insecure attachment pattern, fairly equally divided between ambivalent and avoidant attachment (BakermansKranenburg 2009). Childhood adversity is strongly associated with insecure adult attachment.

\section{Insecure attachment subtypes}

Insecurity of attachment has been empirically divided into three subtypes: avoidant (dismissing), ambivalent and disorganised. Some researchers add a fourth type: anxious or fearful. Those who are avoidant of attachment tend to dismiss distress and need, and avoid closeness to others. A subgroup of avoidant individuals may be actively derogatory about neediness and those who offer care. Those who

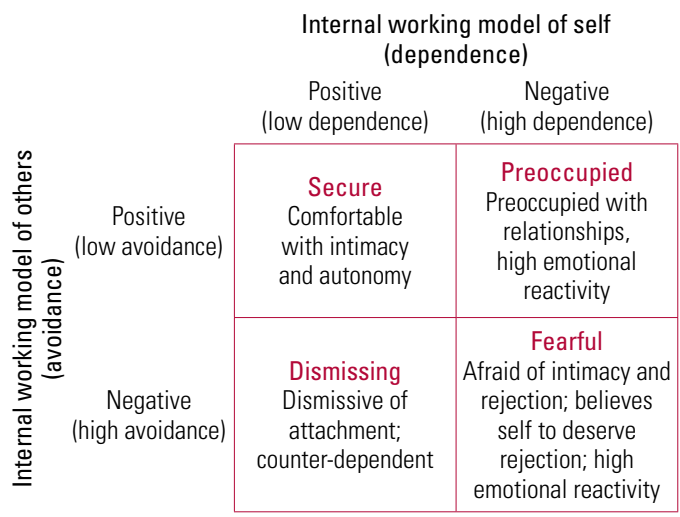

The four-category model of adult attachment (from Ma 2006, after Bartholomew 1991). 
are anxiously attached may be fearful, preoccupied or both. They typically seek closeness to others and express great neediness, but then withdraw or become distressed about help-seeking. Those with disorganised insecurity show elements of avoidant and anxious attachment, and this group is more likely to be diagnosed with clinical psychiatric disorders (Bakermans-Kranenburg 2009).

The common factor across patterns of attachment insecurity is that encounters with attachment figures are unsatisfactory in terms of stress relief and arousal reduction. When people become ill, their attachment systems are activated because illness (and perceived illness) is a life threat and vulnerability is increased. When people identify themselves as 'patients', they usually experience heightened dependence on professional caregivers, which may trigger early internal working models of care-seeking behaviour. Insecurity of attachment could theoretically result in both dysfunctional careeliciting as adults and unsatisfactory relationships with professional caregivers (Table 1).

\section{Assessing attachment: a brief comment}

There is a wide variety of measures with various psychometric properties for assessing different aspects of adult attachment using interview or self-report questionnaires (Roismann 2007; Ravitz 2010). In general, interview methods assess the individual's unconscious representation of childhood care experience and relational dependency, and the defences against any attachment anxiety, whereas self-report questionnaires assess the individual's conscious attachment style, most commonly in relation to other adults as peers or partners.

The most common interview is the Adult Attachment Interview (AAI) (reviewed in Hesse 2008). This generates a narrative text which is analysed linguistically with reference to a manual. The AAI is unwieldy and expensive to administer (although it arguably provides the best assessment of childhood attachment representation). The Parental Bonding Instrument (PBI) (Parker 1979) is a self-report instrument that is easier to administer and also gives an approximation of recalled childhood care.

There are many self-report measures, most of which focus on adult relationships in the 'here and now'. The most commonly used (Fraley 2000) include the Relationships Questionnaire (Bartholomew 1991) and the Experiences in Close Relationships (ECR) scale (Brennan 1998). Attachment researchers such as Shaver and Fraley recommend the use of dimensional measures such as the ECR-R because most individuals' attachment styles involve a degree of security, anxiety, ambivalence and avoidance that changes in different relational contexts.

\section{Attachment insecurity and organic conditions}

\section{Chronic pain}

There has been increasing recognition of the role of adult attachment style in the experience of pain (Meredith 2008). Insecure attachment may be a risk factor for chronic pain that does not respond to ordinary analgesia (Davies 2009). Studies have found that insecure attachment in healthy adults is associated with hypochondriacal beliefs, hypervigilance to pain, increased pain-related fears, reduced pain threshold and poor coping with pain.

Among individuals with chronic pain, insecure attachment is associated with more negative appraisals of pain, increased pain perception and disability, increased psychological distress and impaired coping with pain, and greater utilisation of healthcare services (Ciechanowski 2003).

\section{Diabetes: severity and treatment adherence}

Ciechanowski et al (2001) investigated attachment security in people with type I and type II diabetes attending primary care clinics. Of 367 patients, only $106(28.9 \%)$ were rated as having a secure attachment style: 89 (24.2\%) showed dismissing/avoidant attachment, $85(23.2 \%)$ preoccupied/ambivalent attachment and 73 (19.9\%) fearful attachment. There was a significant association between attachment style and glycosylated haemoglobin $\mathrm{HbA}_{1 \mathrm{C}}$ $(P=0.03)$. Patients with a dismissing attachment style had significantly higher $\mathrm{HbA}_{1 \mathrm{C}}$ than the other groups, indicating such individuals are at a much higher risk for retinopathy because of their higher $\mathrm{HbA}_{1 \mathrm{C}}$ scores. Patients with a dismissing style who rated the quality of provider communication as poor had the worst control over their glucose levels.

TABLE 1 How attachment style affects care-eliciting behaviour and relationships with professional caregivers

\begin{tabular}{|lll|}
\hline Attachment pattern & Attitude to care seeking & Attitude to caregivers \\
\hline Secure & $\begin{array}{l}\text { Positive approach to seeking } \\
\text { help }\end{array}$ & $\begin{array}{l}\text { Trusting, confident, } \\
\text { collaborative, valuing of help }\end{array}$ \\
\hline Dismissing & $\begin{array}{l}\text { Reluctant to seek help or } \\
\text { appear dependent }\end{array}$ & $\begin{array}{l}\text { Suspicious, guarded, keen to } \\
\text { keep interactions brief. May not } \\
\text { adhere to treatment and may } \\
\text { fail to keep appointments }\end{array}$ \\
\hline Ambivalent & $\begin{array}{l}\text { Seeks help when anxious, } \\
\text { but then withdraws }\end{array}$ & $\begin{array}{l}\text { Initially positive but then may } \\
\text { complain and/or be hostile. May } \\
\text { not adhere to treatment }\end{array}$ \\
\hline Anxious/fearful & $\begin{array}{l}\text { Seeks help, but then } \\
\text { withdraws }\end{array}$ & $\begin{array}{l}\text { Engages then withdraws. Is not } \\
\text { reassured by caregiver. May fail } \\
\text { to keep appointments }\end{array}$ \\
\hline $\begin{array}{l}\text { Disorganised attachment } \\
\text { (mixture of dismissing and } \\
\text { fearful) }\end{array}$ & Avoidant and non-engaging & $\begin{array}{l}\text { May be frightened by caregivers } \\
\text { and treatment }\end{array}$ \\
\hline $\begin{array}{l}\text { Derogating of attachment } \\
\text { (extreme dismissing stance) }\end{array}$ & $\begin{array}{l}\text { Avoidant; hostile to idea of } \\
\text { being dependent }\end{array}$ & $\begin{array}{l}\text { May be actively hostile to care- } \\
\text { givers, derogatory about treatment }\end{array}$ \\
\hline
\end{tabular}


Ciechanowski and his team repeated their study of self-care in diabetes in a larger population-based sample (Ciechanowski 2004). In this group of 4095 patients, only $44.2 \%$ were rated as having a secure attachment style; $35.8 \%$ were rated as having a dismissing style. Rates for other insecure styles were lower than usual: $7.9 \%$ for preoccupied and $12.1 \%$ for fearful. The patients with a dismissing attachment style were significantly more likely to take less exercise, have poorer foot care, eat a less healthy diet and smoke, and less likely to adhere to oral hypoglycaemic medication. In a further study of missed appointments in primary diabetic care (Ciechanowski 2006a), again there was an excess of insecure attachment styles (over 60\%) and also a high prevalence of depression.

Poor adherence may be mediated by the effect of patients' attachment style in their relationships with healthcare professionals. In a qualitative study of 27 patients with type II diabetes (purposively sampled), Ciechanowski \& Katon (2006b) found that a subgroup with fearful and dismissing attachment style described low levels of trust and an inability to collaborate with others. These patients also perceived a distinct power differential between healthcare providers and themselves that made them reluctant to engage. The study suggested that the rushed, impersonal nature of modern healthcare interfered with insecure patients' ability to engage.

\section{Other chronic conditions}

Rossi et al (2005) evaluated 200 patients suffering chronic migraine or episodic migraine without aura using the Beck Depression Inventory and the Attachment Style Questionnaire. Disability was more severe in patients with more severe depressive symptoms and insecure style of attachment. In 146 patients, Maunder et al (2005) investigated the influence of attachment style (attachment anxiety and avoidance) on depression during active phases of ulcerative colitis. Attachment insecurity moderated the relationship between disease activity and depressive symptoms. Two more recent studies have found an adverse effect of insecure attachment on the relationships of oncology patients with their doctors (Holwerda 2013; Hillen 2014).

\section{Attachment security and symptom reporting}

In a survey of women enrolled with a US health maintenance organisation (Ciechanowski 2002), 701 of the 1119 individuals contacted completed a self-rating attachment questionnaire. Only 34\% were rated as having secure attachment: almost half of what would be expected in a non-clinical community sample. The insecure attachment styles were fairly evenly divided between fearful (21\%), preoccupied (22\%) and dismissing (23\%).
Attachment style was significantly associated with the number of somatic symptoms reported during a 6-month period (after adjusting for covariables). Individuals with preoccupied and fearful attachment had a significantly greater number of reported somatic symptoms compared with secure individuals; those with dismissing attachment did not. The same study showed greater costs for call outs and attendance for all patients with insecure attachment styles compared with secure.

Taylor et al (2000) specifically investigated attachment style and MUS in a primary care (general practitioner) sample of 2042 consecutive attenders, using the General Health Questionnaire (GHQ) and the Attachment Style Questionnaire. The distribution of attachment security was as would be expected in a community sample, with higher levels of security (77\%) than insecurity (16\% avoidant, $7 \%$ anxious attachment). However, those with insecure attachment styles had higher GHQ scores than normal, with mean scores of 20 (avoidant) and 19 (anxious), compared with the normal mean score of 12 . They were also more likely to attribute any physical discomfort to a physical cause. Patients who presented with unexplained physical symptoms (MUS) were 2.47 times more likely to have insecure attachment. A later study (Taylor 2012) found that insecure attachment style was related to frequent attending in primary care.

Waller et al (2004) used the AAI to assess attachment security in 37 patients with ICD-10 somatoform disorder (without severe physical or mental illness) attending a university hospital, comparing them with 20 matched healthy controls. Only $26 \%$ of the patients were rated as having a secure attachment style, compared with $60 \%$ of the controls. The controls showed the expected frequency of insecure attachment: $25 \%$ dismissing and $15 \%$ preoccupied. In contrast, the patients had high levels of dismissing (48.6\%) and preoccupied (25.7\%) attachment styles.

\section{Attachment insecurity as risk factor for MUS: possible pathogenic mechanisms}

The development of the attachment system might influence the risk of later MUS in a variety of ways, for example greater susceptibility to stress in adulthood, increased use of external sources of affect regulation and altered help-seeking behaviour (Hunter 2001). We discuss here two further possibilities.

\section{Attachment insecurity, embodied cognition and somatic markers of emotion}

Dalgleish (2004) reviews the theoretical basis for understanding how emotions are embodied. He describes a variety of brain areas that are thought to 
be active in the experience of embodied cognitions. These include the right orbitofrontal cortex, the limbic system and the anterior cingulate cortex. The development of these areas is a complex process that begins at birth and continues into the second decade of life (Smith 2005).

Newborn babies develop neural systems that integrate somatic experience into responses that are discriminating and fine tuned. By 2 or 3 years of age, children can reliably identify where a pain is on the body; and by school age, they can report pain that does not have an organic basis. The attachment relationship between infant and carer influences the development of both the sympathetic and parasympathetic (autonomic) nervous systems. Specifically, it affects arborisation and dendritisation of neural networks across the cortex and subcortical areas (Schore 2001). Exposure to traumatic stress, including severe disruptions to the attachment relationship, interferes with the development of the frontal cortical executive that acts to regulate unconscious inputs from the parasympathetic nervous system innervating the gut, cardiac system, endocrine system and muscles.

Damasio et al (1996) have hypothesised that the emotions are experienced first in the body, which acts as an unconscious 'somatic marker' for cognitive 'feelings'. Emotions are communicated to the brain in the unconscious parasympathetic system and elaborated by the neocortex into the 'feelings' that we appreciate consciously. The work of both Schore and Damasio et al emphasises the role of the frontal cortex in organising and managing somatic experience within an entire framework of self-experience. The right orbitofrontal cortex in particular seems to be important for correct identification of somatic perceptual experience.

Techniques involving the study of the brain are still in their relative infancy and it remains to be seen whether specific cognitive/emotional processes map onto discrete areas of the brain. Connections and processing far more complex than can be studied at present are likely to be involved in this complicated area. It is clear that the experiencing of physical sensation involves both peripheral and central processing, but the balance may vary widely even in the same individual. As knowledge develops in this area, the term 'medically unexplained' will become redundant, as evidence suggests that it is the total number or 'burden' of somatic symptoms and the patients' concern about those symptoms that best predict both disability and future healthcare use (Tomenson 2013).

Childhood trauma, attachment insecurity and MUS

Early childhood adversity is a known risk factor for both poor physical health and MUS in adulthood.
This risk relationship may be mediated by insecurity of attachment, which is also known to be associated with early childhood adversity. Children who are exposed to maltreatment by a carer not only experience repeated physical pain and fear arising from these assaults, but also are unable to turn to that carer to manage their distress. Repeated stress and hyperarousal owing to lack of care may damage normal development, in terms of either the somatic response to stress or dysregulation of cognitive and affective responses to somatic stimuli (Weich 2009; Norman 2012).

\section{Dysfunction in the patient-doctor relationship}

Attachment might also mediate the relationship between childhood trauma and MUS in adulthood through its effect on relationships with healthcare professionals from whom the person has to elicit care. Repetition of an insecure attachment pattern can lead to dysfunctional relationships with healthcare professionals that influence illness management and treatment adherence. Some people with MUS perceive healthcare professionals to be insufficiently caring, interested or concerned, just like their original carers. Some at the severe end of the spectrum have thick medical files because they go from doctor to doctor, repeating a complex and dysfunctional attachment relationship. Maunder et al (2006) found that the difficulties that doctors experienced with patients were related to the patients' attachment styles.

The dysfunction in the caring relationship goes both ways: there is an extensive literature on the negative response of doctors to patients who 'don't or won't get better'. Examples from general practice include the 'heartsink' patient (O'Dowd 1988) and the 'hateful patient' (Groves 1978), and it is likely that hostility from healthcare professionals has a negative effect on the care offered to patients with MUS. Salmon et al (2008) describe how doctors' own attachment styles influence what they offer to patients with MUS.

\section{Alexithymia}

Another possible mechanism linking trauma, attachment theory and MUS is alexithymia: the inability to put feelings into words. There has been considerable study of whether people with psychosomatic disorders have higher than usual levels of alexithymia compared with normal populations; there is evidence both for and against the hypothesis (Kooiman 1998). Some researchers have postulated a general role for alexithymia in MUS, suggesting that it night be a mediating factor for somatisation in adults who have experienced childhood trauma (Waldinger 2006). Alexithymia may influence the way that patients with MUS can 
talk to healthcare professionals and thus adversely affect the medical relationship.

\section{Interventions}

At the primary care level in the UK, IAPT services offer brief interventions for MUS. A wide variety of psychological techniques have been shown to be of benefit (Creed 2011b), including cognitivebehavioural therapy, psychodynamic interpersonal therapy, mindfulness-based approaches and hypnosis. Multicomponent behavioural packages and antidepressants have also been successful.

Most of the psychological approaches involve working with the person's physical symptoms and obtaining the person's story of their illness and how it has affected them and their family. There is evidence that people with MUS in primary care may be receptive to ideas about stress as a causative factor and value doctors who can develop with them a shared understanding and model of illness. The cognitive-behavioural therapies tend to focus on developing positive coping strategies and encouraging physical function. Mindfulness-based cognitive therapy (MBCT) and mindfulness-based stress reduction (MBSR) have been shown to be helpful for both chronic depression and chronic pain, and they may therefore indirectly improve MUS (Bohlmeijer 2010). Mindfulness-based practices may also help with MUS by improving regulation of negative affect and helping patients change their awareness and relationships with bodily experience and pain.

Another therapy that pays particular attention to 'here-and-now' bodily experience is psychodynamic interpersonal therapy (Hobson 1985). The focus is on 'forms of feelings'. This notion involves not just emotions, but physical bodily feelings that connect with an image, idea or other similar experience. People are encouraged to stay with their 'feelings' in the session, so that these are experienced here and now, in the context of a relationship. As the forms of feeling develop, links emerge between physical experience, emotions and relationships.

\section{Severe symptoms}

At the more severe end of the spectrum, some people with MUS will experience their body as alien, uncomfortable or 'sick' in a variety of ways. Such people may feel hostility and/or fear in relation to their discomfort and distress, in addition to a sense of being overwhelmed and helpless. They may lack compassion towards their bodies and minds (RaqueBogdan 2011) and experience anger with 'carers' who fail to relieve their distress. Reassurance, information and/or logical analysis alone are unlikely to transform such people's experiences of bodily distress. What is needed is a 'change of tack', as described by Bass \& Glaser (2014a), away from any sense of confrontation or challenge and towards a way of working that emphasises positive function and activity while also taking seriously attachmentbased affects of anger, fear and hostility towards the self and others. Clinical experience suggests that more intensive therapies addressing underlying cognitive schema or affectful beliefs may be helpful, and in-patient treatment programmes using a range of interventions, including interpersonal and family work, have shown promise.

\section{Patient-specific intervention}

An appreciation of attachment theory suggests that it may also be important to offer different types of intervention to different groups, distinguished by attachment insecurity. Assessment of attachment style as part of a general assessment is likely to give some idea of how a person deals with their own dependency needs and relates to healthcare professionals. People with different attachment styles will respond in different ways to different interventions. Dismissing individuals may be unlikely to engage with any intervention that focuses on psychological distress, but they may accept interventions that address their physical experience, such as mindfulness practices, health information and exercise programmes. People with fearful and preoccupied attachment may respond better to an intervention that actively invites reflection on the link between their psychological distress, physical experience and childhood trauma.

A modified version of this approach is described by Ciechanowski et al (2006a), who divided 324 patients with diabetes and comorbid depression into two groups: those with an insecure attachment (relationship) style, who were deemed 'independent'; and those with a secure attachment style, who were deemed 'interactive'. Patients in both groups were randomly assigned either to an intervention designed to improve quality of depression care or to care as usual. For patients deemed 'independent', the intervention resulted in significantly more painfree days at 12-month follow-up compared with care as usual, whereas for patients deemed 'interactive' (i.e. with a secure relationship style) there was no significant difference in depression outcomes. The authors speculated that the secure group did not benefit from the programme of care because they were already able to do for themselves many of the things that were offered. The insecure patients, however, were not able to do these thing without help, and therefore got the most benefit from the intervention. The marked differences in outcome between the groups suggest that further work in 
this area would be of value. It may be that people with secure attachments require minimal input in relation to treatment, and we should be focusing attention much more on people with insecure attachment styles. This is the only study of which we know that has examined differential response rates to therapy according to attachment status.

\section{Somatising disorders in parents}

It is vital that parents with somatising disorders are identified and treated early, especially mothers who are largely responsible for their young children's healthcare and interactions with healthcare professionals. There is evidence of transmission of somatising behaviours and health beliefs across the generations (Craig 2002; Marshall 2007), and children who are frequent attenders in primary care tend to have parents who have complex relationships with healthcare providers (Little 2001). A subgroup of mothers with somatising disorders form highly dysfunctional relationships with professional carers and expose children to unnecessary examinations, investigations and treatments (Bass 2014b).

\section{Conclusions}

There is extensive evidence that attachment security influences how people experience their body on a day-to-day basis; how they interpret pain or dysfunction; how they manage stress associated with illness; and how they relate to caregivers, both personal and professional. Attachment style can buffer or increase the perceived stress of illness (either explained or unexplained) and can influence response to psychological interventions aimed at reducing MUS. Attachment style may mediate between childhood abuse and adult somatisation. Consequently, when assessing patients who struggle with physical illness, it is essential to take an extensive developmental history that addresses not only childhood experience of loss and stress, but also histories of illness and distress in the family. Clinicians need to develop interventions that 'fit' the attachment narratives of individual patients, rather than forcing patients into one-size-fits-all psychological therapeutic techniques.

\section{References}

Aggarwal VR, McBeth J, Zakrzewska JM, et al (2006) The epidemiology of chronic syndromes that are frequently unexplained: do they have common associated factors? International Journal of Epidemiology, 35 : 468-76.

Ainsworth MDS, Bell SM (1970) Attachment, exploration, and separation: illustrated by the behavior of one-year-olds in a strange situation. Child Development, 41: 49-67.

Bakermans-Kranenburg MJ, van IJzendoorn MH (2009) The first 10,000 Adult Attachment Interviews: distributions of adult attachment representations in clinical and non-clinical groups. Attachment \& Human Development, 11: 223-63.
Bartholomew K, Horowitz LM (1991) Attachment styles among young adults: a test of a four-category model. Journal of Personality and Social Psychology, 61: 226-44.

Bass C, Glaser D (2014a) Early recognition and management of fabricated or induced illness in children. Lancet, 383: 1412-21.

Bass C, Acosta C, Adshead G, et al (2014b) Fabrication and induction of illness in children. In Clinical Topics in Child and Adolescent Psychiatry (ed S Huline-Dickens): 10-25. RCPsych Publications.

Bohlmeijer E, Prenger R, Taal E, et al (2010) The effects of mindfulnessbased stress reduction therapy on mental health of adults with a chronic medical disease: a meta-analysis. Journal of Psychosomatic Research, 68: 539-44.

Brennan KA, Clark CL, Shaver PR (1998) Self-report measurement of adult attachment: an integrative overview. In Attachment Theory and Close Relationships (eds JA Simpson, WS Rholes): 46-76. Guilford Press.

Ciechanowski PS, Katon WJ, Russo JE, et al (2001) The patient-provider relationship: attachment theory and adherence to treatment in diabetes. American Journal of Psychiatry, 158: 29-35.

Ciechanowski PS, Walker EA, Katon WJ, et al (2002) Attachment theory: a model for health care utilization and somatization. Psychosomatic Medicine, 64: 660-7.

Ciechanowski P, Sullivan M, Jensen M, et al (2003) The relationship of attachment style to depression, catastrophizing and health care utilization in patients with chronic pain. Pain, 104: 627-37.

Ciechanowski P, Russo J, Katon W, et al (2004) Influence of patient attachment style on self-care and outcomes in diabetes. Psychosomatic Medicine, 66: 720-8.

Ciechanowski P, Russo J, Katon W, et al (2006a) The association of patient relationship style and outcomes in collaborative care treatment for depression in patients with diabetes. Medical Care, 44: 283-91.

Ciechanowski P, Katon W (2006b) The interpersonal experience of health care through the eyes of patients with diabetes. Social Science \& Medicine, 63: 3067-79.

Craig TKJ, Cox AD, Klein K (2002) Intergenerational transmission of somatization behaviour: a study of chronic somatizers and their children. Psychological Medicine, 3: 805-16.

Creed F, Barksi A, Leiknes KA (2011a) Epidemiology: prevalence, causes and consequences. In Medically Unexplained Symptoms, Somatisation and Bodily Distress: Developing Better Clinical Services (eds F Creed, P Henningsen, P Fink): 1-42. Cambridge University Press.

Creed F, Kroenke K, Henningsen P, et al (2011b) Evidence-based treatment. In Medically Unexplained Symptoms, Somatisation and Bodily Distress: Developing Better Clinical Services (eds F Creed, P Henningsen, P Fink): 69-96. Cambridge University Press.

Dalgleish T (2004) The emotional brain. Nature Reviews Neuroscience, 5: 583-9.

Damasio AR, Everitt BJ, Bishop D (1996) The somatic marker hypothesis and the possible functions of the prefrontal cortex. Philosophical Transactions of the Royal Society of London. Series B: Biological Sciences, 351: 1413-20.

Davies KA, Macfarlane GJ, McBeth J, et al (2009) Insecure attachment style is associated with chronic widespread pain. Pain, 143: 200-5.

Eriksen TE, Kirkengen AL, Vetlesen AJ (2013) The medically unexplained revisited. Medicine, Health Care and Philosophy, 16: 587-600.

Fraley RC, Waller NG, Brennan KA (2000) An item response theory analysis of self-report measures of adult attachment. Journal of Personality and Social Psychology, 78: 350-65.

George C, Kaplan N, Main M (1985) Adult Attachment Interview. Department of Psychology, University of California.

Groves J (1978) Taking care of the hateful patient. New England Journal of Medicine, 298: 883-7.

Gwee KA, Read NW, Graham JC, et al (1996) Psychometric scores and persistence of irritable bowel after infectious diarrhoea. Lancet, 347 : 150-3.

Hamilton WT, Gallagher AM, Thomas JM, et al (2009) Risk markers for both chronic fatigue and irritable bowel syndromes: a prospective casecontrol study in primary care. Psychological Medicine, 39: 1913-21. 


\section{MCO answers \\ $\begin{array}{lllll}1 \mathrm{c} & 2 \mathrm{~d} & 3 \mathrm{~d} & 4 \mathrm{e} & 5 \mathrm{a}\end{array}$}

Hartman TO, Blankenstein N, Molenaar B, et al (2013) NHG guideline on medically unexplained symptoms (MUS). Huisarts \& Wetenscap, 56 : $222-30$

Hesse E (2008) The Adult Attachment Interview: protocol, method of analysis, and empirical studies. In Handbook of Attachment: Theory, Research, and Clinical Applications (2nd edn) (eds J Cassidy, P Shaver): 552-98. Guilford Press.

Hillen MA, de Haes HC, Stalpers LJ, et al (2014) How attachment style and locus of control influence patients' trust in their oncologist. Journal of Psychosomatic Research, 76: 221-6.

Hobson RF (1985) Forms of Feeling: The Heart of Psychotherapy. Routledge.

Holwerda N, Sanderman R, Pool G, et al (2013) Do patients trust their physician? The role of attachment style in the patient-physician relationship within one year after a cancer diagnosis. Acta Oncologica, 52: $110-7$

Hunter JJ, Maunder RG (2001) Using attachment theory to understand illness behavior. General Hospital Psychiatry, 23: 177-82.

Improving Access to Psychological Therapies (2015) Medically unexplained symptoms. National Health Service (http://www.iapt.nhs.uk/ Itcmus/medically-unexplained-symptoms). Accessed 24 Mar 2015.

Kooiman CG (1998) The status of alexithymia as a risk factor in medically unexplained physical symptoms. Comprehensive Psychiatry, 39: 152-9.

Little P, Somerville J, Williamson I, et al (2001) Family influences in a cross-sectional survey of higher child attendance. British Journal of General Practice, 51: 977-82.

Ma K (2006) Attachment theory in adult psychiatry. Part 1: Conceptualisations, measurement and clinical research findings. Advances in Psychiatric Treatment, 12: 440-9.

Marshall T, Jones DPH, Ramchandani PG, et al (2007) Intergenerationa transmission of health beliefs in somatoform disorders: exploratory study. British Journal of Psychiatry, 191: 449-50.

Maunder RG, Lancee WJ, Hunter JJ, et al (2005) Attachment insecurity moderates the relationship between disease activity and depressive symptoms in ulcerative colitis. Inflammatory Bowel Diseases, 11: 919-26.

Maunder RG, Panzer A, Viljoen M, et al (2006) Physicians' difficulty with emergency department patients is related to patients' attachment style. Social Science \& Medicine, 63: 552-62.

Maunder RG, Hunter JJ (2008) Attachment relationships as determinants of physical health. Journal of the American Academy of Psychoanalysis and Dynamic Psychiatry, 36: 11-32.

Meredith P, Ownsworth T, Strong J (2008) A review of the evidence linking adult attachment theory and chronic pain: presenting a conceptual model. Clinical Psychology Review, 28: 407-29.

Norman RE, Byambaa M, De R, et al (2012) The long-term health consequences of child physical abuse, emotional abuse, and neglect: a systematic review and meta-analysis. PLoS Medicine, 9(11): e1001349.
O'Dowd TC (1988) Five years of heartsink patients in general practice. BMJ, 297: 528-30.

Parker G, Tupling H, Brown LB (1979) Parental Bonding Instrument (PBI). British Journal of Medical Psychology, 52: 1-10.

Raque-Bogdan TL, Ericson SK, Jackson J, et al (2011) Attachment and mental and physical health: self-compassion and mattering as mediators. Journal of Counseling Psychology, 58: 272-8.

Ravitz P, Maunder R, Hunter J, et al (2010) Adult attachment measures: a 25-year review. Journal of Psychosomatic Research, 69: 419-32.

Roisman GI, Holland A, Fortuna K, et al (2007) The Adult Attachment Interview and self-reports of attachment style: an empirical rapprochement. Journal of Personality and Social Psychology, 92: 678-97.

Rossi P. Di Lorenzo G, Malpezzi MG, et al (2005) Depressive symptoms and insecure attachment as predictors of disability in a clinical population of patients with episodic and chronic migraine. Headache: The Journal of Head and Face Pain, 45: 561-70.

Salmon P. Wissow L, Carroll J, et al (2008) Doctors' attachment style and their inclination to propose somatic interventions for medically unexplained symptoms. General Hospital Psychiatry, 30: 104-11.

Schore AN (2001) The effects of early relational trauma on right brain development, affect regulation, and infant mental health. Infant Mental Health Journal, 22: 201-69.

Sharpe M, Stone J, Hibberd C, et al (2010) Neurology out-patients with symptoms unexplained by disease: illness beliefs and financial benefits predict 1 year outcome. Psychological Medicine, 40: 689-98.

Smith L, Gasser M (2005) The development of embodied cognition: six lessons from babies. Artificial Life, 11: 13-29.

Stone J, Carson A, Duncan R, et al (2009) Symptoms unexplained by organic disease in 1144 new neurology out-patients: how often does the diagnosis change at follow-up? Brain, 132: 2878-88.

Taylor RE, Mann AH, White NJ, et al (2000) Attachment style in patients with unexplained physical complaints. Psychological Medicine, 30: 931-41.

Taylor RE, Marshall T, Mann A, et al (2012) Insecure attachment and frequent attendance in primary care: a longitudinal cohort study of medically unexplained symptom presentations in ten UK general practices. Psychological Medicine, 42: 855-64.

Tomenson B, Essau C, Jacobi F, et al (2013) Total somatic symptom score as a predictor of health outcome in somatic symptom disorders. British Journal of Psychiatry, 203: 373-80.

Waldinger RJ, Schulz MS, Barsky AJ, et al (2006) Mapping the road from childhood trauma to adult somatization: the role of attachment. Psychosomatic Medicine, 68: 129-35.

Waller E, Scheidt CE, Hartmann A (2004) Attachment representation and illness behavior in somatoform disorders. Journal of Nervous and Mental Disease, 192: 200-9.

Weich S, Patterson J, Shaw R, et al (2009) Family relationships in childhood and common psychiatric disorders in later life: systematic review of prospective studies. British Journal of Psychiatry, 194: 392-8.

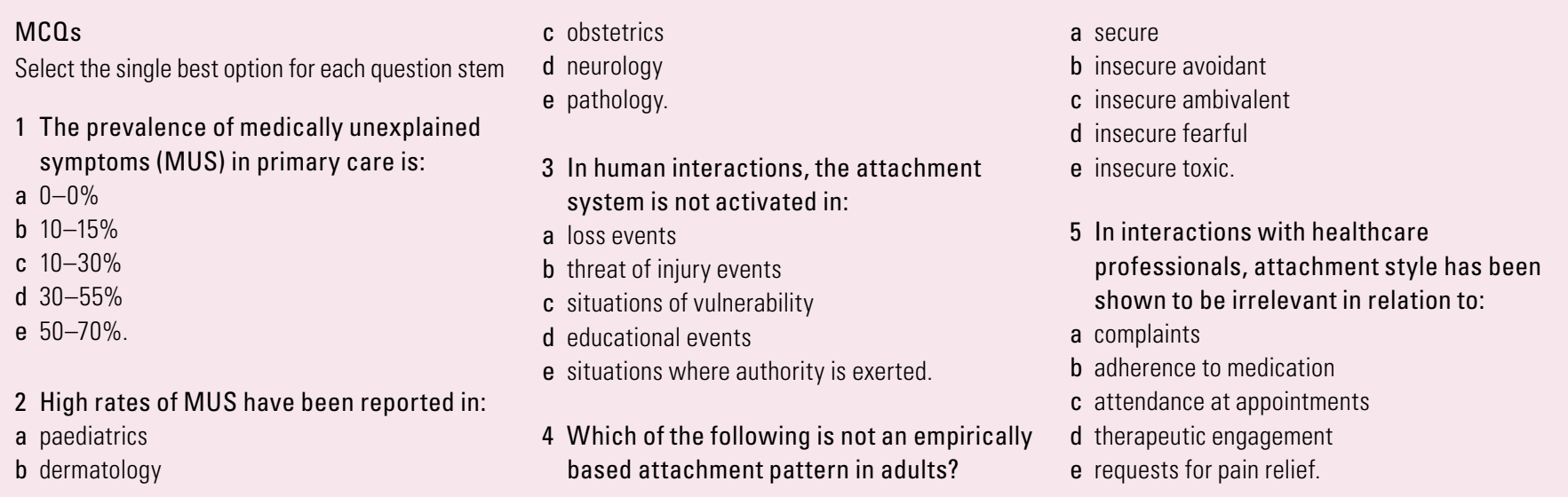

